\title{
Arte da América Latina na crítica de arte de Raymond Cogniat, 1926
}

\section{Latin American art in art criticism of Raymond Cogniat , 1926}

Renata Gomes Cardoso ${ }^{1}$

Resumo Apresenta-se aqui uma tradução para o português do texto "Les peintres de L'Amérique Latine", escrito pelo historiador e crítico de arte francês Raymond Cogniat, que foi publicado em agosto de 1926 na revista francesa La Renaissance de l'art français et des industries de luxe. Esta edição foi inteiramente dedicada às artes da América Latina e incluía análises sobre a arquitetura, a escultura, as artes decorativas, além de um texto final sobre a situação dos estudos latino-americanos na França. Raymond Cogniat também escreveu vários artigos sobre artistas latino-americanos na Revue de l'Amérique Latine, importante publicação que apresentava informações, opiniões e debates sobre política, história, literatura e arte da América Latina.

Palavras-chave arte latino-americana; revistas francesas; crítica de arte.

Abstract This paper presents a translation into Portuguese of the text "Les peintres de L'Amérique Latine", written by the French art historian and critic Raymond Cogniat and published in 1926 in the art journal La Renaissance de l'art français et des industries de luxe. This edition was entirely devoted to the arts of Latin America, providing analysis on architecture, sculpture and decorative arts, with a final text on Latin American Studies in France. Raymond Cogniat also wrote many articles about Latin American artists in the Revue de l'Amérique Latine, an important publication that presented subjects such as politics, history, literature and arts, for the French audience.

Keywords Latin American Art; French Journals; Art Criticism.

Tradução recebida em: 01/07/2015

Tradução aprovada para publicação em: 15/11/2015

\footnotetext{
${ }^{1}$ Doutora em Artes, na área de História da Arte, pelo Instituto de Artes da Unicamp e Mestre em História, na área de História da Arte, pelo Instituto de Filosofia e Ciências Humanas da Unicamp. Pós-doutoranda no Museu de Arte Contemporânea da USP (MAC-USP), com a pesquisa "Artistas brasileiros no acervo do MAC-USP e a crítica de arte francesa nos anos de 1920”, com financiamento do PNPD/CAPES. Email: regomescardoso@gmail.com
}

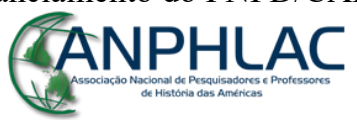

Revista Eletrônica da ANPHLAC, ISSN 1679-1061, №. 19, p. 252-267, jul./dez., 2015. http://revista.anphlac.org.br 
Em 1926, abria-se em Paris uma Exposição de Arte Argentina, dentre as inúmeras exposições de arte que a cidade abrigava nos anos de entre guerras. Caracterizada por um internacionalismo crescente, a capital das artes voltou sua atenção para essa exposição que, somada à participação assídua de latino-americanos nos principais salões de arte franceses, chamou a atenção da crítica de arte. A revista francesa La Renaissance de l'art français et des industries de luxe dedicou nesse ano uma edição inteira à arte latino-americana, abordando desde a arquitetura e objetos dos tempos pré-colombianos à pintura e escultura da década de 1920. ${ }^{2}$ Todos os artigos publicados nesse número especial são bilíngues, escritos em francês, mas com tradução para o espanhol feita por Mathilde Pòmes, mesma autora do último artigo, que versa sobre a situação dos estudos latino-americanos em Paris.

A revista La Renaissance foi criada, por sua vez, em 1918 por Henri Lapauze ${ }^{3}$, como uma continuidade, em separado, do suplemento dedicado às artes da revista $L a$ Renaissance politique, littéraire, économique et artistique, fundada também por ele em 1913. Essa publicação era bastante conhecida e exerceu grande influência no cenário cultural francês dos anos de $1920^{4}$, o que induz a uma reflexão sobre a relevância e a difusão do tema da América Latina naquele meio, já que levou a revista a reservar uma edição especial para a exposição e análise da arte latino-americana em suas várias formas de expressão, seja pela observação de monumentos do passado ou das produções mais recentes. O fato de esse número da revista apresentar a atuação de artistas contemporâneos que circulavam em Paris naquele momento, ao lado das mais recentes pesquisas europeias sobre a história dos povos pré-colombianos, ponto que desde muito despertava o interesse do ocidente, demonstra que havia também uma intenção

\footnotetext{
${ }^{2}$ Trata-se de La Renaissance de l'art français et des industries de luxe, n. 8, agosto de 1926, cuja edição foi publicada bilíngüe, em francês e espanhol, e todos os artigos abordaram algum aspecto da arte latino-americana. A revista se encontra digitalizada na biblioteca digital (Gallica) da Bibliothèque Nationale de France (BnF). Disponível em: http://gallica.bnf.fr/ark:/12148/bpt6k6150727w.image.langFR.r=la\%20reinaissance\%20de\% 20l'art\%20fran\%C3\%A7ais\%20et\%20des\%20industries. Acesso em: 23 de março de 2012.

${ }^{3}$ Historiador, crítico de arte e diretor do Petit Palais em Paris, Henri Lapauze nasceu em Montauban, cidade natal do renomado artista Jean-Auguste-Dominique Ingres, muito cultuado nos anos de pós-guerra na França, em vista do clima cultural de Retorno à Ordem que caracterizou boa parte das produções artísticas do período, como uma reflexão ou mesmo reação frente às transformações mais recentes no âmbito da arte e da cultura propostas pelas vanguardas de início do século XX.

${ }^{4}$ Para uma contextualização de muitas dessas revistas, que apresentavam diferentes filiações a diversas tendências em circulação na França ver, por exemplo, DESBIOLLES (2014).
}

\section{CANPHLAC}

Revista Eletrônica da ANPHLAC, ISSN 1679-1061, N. 19, p. 252-267, jul./dez., 2015.

http://revista.anphlac.org.br 
em evidenciar a grande circulação desses artistas em Paris, a "capital das artes" da Europa naqueles anos.

Ao contrário desse enfoque dado por La Renaissance nesse ano, a atuação dos artistas latino-americanos na cena artística francesa era normalmente analisada na crítica de arte de uma maneira mais pulverizada, em pequenas citações que apareciam em jornais e revistas, geralmente indicando esses artistas por sua nacionalidade, e não necessariamente pela ideia do conjunto "latino-americano", dentre o grande grupo de artistas estrangeiros de vários países que procuravam a França para aperfeiçoamento. A observação da participação dos estrangeiros no contexto artístico parisiense se dava, sobretudo, no âmbito dos principais salões de arte da cidade, nos quais os latino-americanos sempre se apresentavam. Esta presença pode ser observada tanto em salões tradicionais, como o famoso Salon des Artistes Français, quanto nos modernos, como o Salon des Indépendants e o Salon d'Automne.

Nas indicações e análises sobre as propostas dos artistas latino-americanos, o peso do passado de cada país, entendido como diferente, original, autêntico ou exótico, aparecia sempre como paradigma para interpretar e acompanhar o desenrolar da arte dessas culturas genuínas após a colonização, considerando o momento de instituição das práticas artísticas europeias. No caso do Brasil, por exemplo, essa instituição se deu no início do século XIX, com a vinda da Missão Artística Francesa e a posterior criação da Academia Imperial de BelasArtes, que seguia o modelo francês de produção de obras e monumentos. Muitas vezes, os artistas em estágio na Europa eram figuras em passagem que retornariam a seus países, como agentes de transformação da cultura, de forma geral, na direção de uma vida moderna, pelo paradigma europeu, o que por vezes era interpretado pela crítica como um risco de rompimento com esse passado, que era considerado muito rico e significativo. ${ }^{5}$

Esse clima de exaltação dessas culturas no contexto francês era aos poucos compreendido e assimilado pelos artistas latino-americanos, ao mesmo tempo em que a necessidade de diferenciação dos modelos artísticos europeus era reforçada pelos críticos, no que tange principalmente aos temas escolhidos para as obras, embora as premissas da arte

\footnotetext{
${ }^{5}$ Para essa análise foram observadas críticas de arte publicadas isoladamente sobre os artistas latino-americanos, nos anos de 1920, sobretudo no âmbito dos salões mencionados, em revistas e jornais como L'Intransigeant, Le Crapouillot, L'Art et les Artistes, Le Bulletin de la Vie Artistique, Gazette des beaux-arts, dentre tantos outros. A participação desses artistas nos salóes foi levantada com a leitura dos respectivos catálogos, ao longo da década de 1920.
}

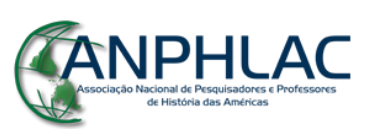

Revista Eletrônica da ANPHLAC, ISSN 1679-1061, N. 19, p. 252-267, jul./dez., 2015.

http://revista.anphlac.org.br 
moderna do período devessem ser colocadas em pesquisa, para atestar sua contemporaneidade e visão crítica quanto às linguagens do passado, que deveriam ser abandonadas. O texto de Raymond Cogniat publicado na revista revela esse tipo de análise, em diversas passagens em que elogia, por exemplo, os artistas que conseguiam atingir esse tipo de síntese, garantindo a referência a seu passado na articulação das linguagens do presente, ou seja, evidenciando as diferentes características de sua cultura em uma obra caracteristicamente moderna, via novas linguagens da arte europeia, talvez o único ponto que garantia o seu comentário na crítica.

Esse tipo de interpretação, porém, não era uma exclusividade dada aos artistas latino-americanos. A capacidade de elaborar uma síntese autêntica entre diferentes tradições, de acordo com o vocabulário da pintura moderna, era normalmente a razão que destacava o artista estrangeiro em um ambiente cultural que exaltava, acima de tudo, um ideário nacionalista, como consequência do contexto da guerra. Um artigo de um dos colaboradores da revista, Arsène Alexandre, publicado na edição de julho de 1926, é um bom exemplo desse tipo de interpretação. O texto apresenta o Salon des Tuileries ${ }^{6}$ daquele ano, enfocando no caso uma obra de Leonard-Tsugouharu Foujita (1886-1969), artista japonês radicado na França. Foujita já era muito conhecido na cena artística francesa dos anos de 1920, por sua relação com modernistas franceses, e a obra exposta foi lida por Arsène Alexandre como "uma saborosa mistura" entre a tradição artística japonesa e a europeia, o que demonstrava uma "aliança perfeita entre o gênio de sua raça e aquele da França, seu país de eleição".

Essa questão de exaltação nacionalista pode ser compreendida contextualizando o momento de nascimento da revista, no final da Primeira Guerra Mundial. O intuito de sua criação fora justamente o de expor e articular em seus textos um "renascimento artístico e intelectual da França"7, baseado na retomada de certos artistas e tendências, atuais ou do passado, que se destacavam como modelos, por excelência, de uma verdadeira tradição artística francesa. Por esse caráter, a revista exercia uma crítica às tendências de ruptura mais acentuadas

\footnotetext{
${ }^{6}$ O Salon des Tuileries foi criado na década de 1920, por iniciativa de artistas descontentes com a Société Nationale des Beaux-Arts - Antoine Bourdelle, Charles Despiau, dentre outros dissidentes, como Albert Besnard, Maurice Denis e George Desvallières, que criaram um novo grupo e improvisaram uma exposição no jardim das Tulherias (Jardin des Tuileries), com montagens em madeira feitas pelo arquiteto August Perret, estabelecendo assim o Salon des Tuileries, que passou a ser realizado anualmente, como outros salões da capital francesa.

${ }^{7}$ Esse caráter nacionalista pode ser observado, por exemplo, no primeiro texto da edição inaugural da revista, de 1928. Ver ALEXANDRE, Arsène. Les Renaissances et les Crises de l'Art Français et des Industries Artistiques. La Renaissance de l'art français et des industries de luxe, n. 1, março, 1918, p. 1-2.
}

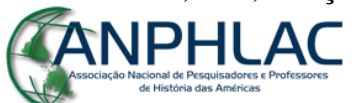

Revista Eletrônica da ANPHLAC, ISSN 1679-1061, N. 19, p. 252-267, jul./dez., 2015.

http://revista.anphlac.org.br 
do período, da vanguarda característica do pré-guerra ${ }^{8}$. Nos primeiros números, publicados ao longo de 1918, o primeiro artigo trazia sempre a assinatura de Arsène Alexandre, que no editorial inicial, de 1918, expôs um debate sobre o renascimento e as crises da arte francesa, o que ilustrava a posição ideológica da revista, por um lado contrária a um academismo artístico banal, falsamente tradicional, porém estéril, e de outro, contrário a certos exageros e experiências na arte, criticando sua falsa ou pretensa renovação, sobretudo aquelas observadas nas artes decorativas. A revista se colocava assim em defesa do patrimônio e da arte francesa, embora incluíssem artistas de filiações muito diferentes, como Otto Friesz, Marc Chagall, Henry Ottman e André Lhote. Este último, por exemplo, havia publicado com Albert Gleizes o famoso texto sobre o cubismo, intitulado Du Cubisme, colocando esse movimento como uma das transformações artísticas que coroavam a "evolução" da arte francesa até aquele momento.

Considerando o internacionalismo do ambiente francês ao longo dos anos de 1920, o destaque dado à arte latino-americana por essa revista, em 1926, não foi um fato isolado, tendo importantes antecedentes. A arte latino-americana procurava se estruturar, institucionalmente falando, no ambiente de Paris, através de diversas iniciativas, que tentaram agrupar intelectuais e artistas por via de eventos, exposições e palestras, de forma que pudessem ganhar mais destaque e projeção no meio parisiense. Em maio de 1923, por exemplo, fora inaugurada a Maison de l'Amérique Latine, dentro de um projeto ambicioso de estabelecimento de uma Académie Internationale des Beaux-Arts ${ }^{9}$, por iniciativa de "dois sul-americanos, Alejandro de Olazabal e Pedro Osório", auxiliados por "um comitê de patrocínio francês"10. A

\footnotetext{
${ }^{8}$ Sobre o caráter mais conservador da referida revista no contexto do pós-guerra, se comparada com outros periódicos tidos como vanguardistas, ver também SILVER, Kenneth E. Esprit de corps: the art of the Parisian avant-garde and the First World War,1914-1925. Princeton: Princeton Univ., 1989, além do já citado Les revues d'art à Paris 1905-1940, que apresenta análises do caráter de cada revista do período.

${ }^{9}$ A criação dessa academia foi anunciada no Journal officiel de la République française. Lois et décrets de 26-27 de dezembro de 1922, p. 1236. O anúncio diz o seguinte: "29 de novembro de 1922. Academia Internacional de Belas Artes. Objetivo: permitir aos estudantes e artistas estrangeiros, principalmente da América Latina, vir à França para realizar seus estudos e expor suas obras. Sede: 11 bis, Avenida Haussmann, Paris." (traduzido pela autora). E a sequência, anunciando a criação da Maison, foi anunciada no Journal officiel de la République française. Lois et décrets de 11 de fevereiro de 1923, p. 1506: "10 de fevereiro de 1923. Associação: Casa da América Latina, Academia Internacional de Belas Artes, que tem como objetivo fundar a Casa da América Latina e de organizar, sob a denominação 'Academia Internacional de Belas Artes' um instituto de ensino superior que agrupará, em sessões determinadas, mestres e alunos, para desenvolver, via um ensino superior de belas artes, uma unidade de pensamento e principalmente de intercâmbio entre os artistas da América Latina e os da França. Sede: 11 bis, Avenida Haussmann, Paris." (tradução da autora).

${ }^{10}$ Cf. BATISTA, Marta Rossetti. Os artistas brasileiros na Escola de Paris - Anos 20. Tese de doutorado, USP, 1987, p. 131.
}

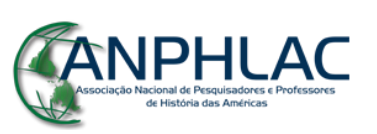

Revista Eletrônica da ANPHLAC, ISSN 1679-1061, №. 19, p. 252-267, jul./dez., 2015.

http://revista.anphlac.org.br 
criação dessa instituição foi divulgada na imprensa do período, com pareceres publicados em jornais como La Presse e La Semaine à Paris. Para a inauguração foi organizada uma mostra de artes, da qual participaram artistas de vários países da América Latina, dentre eles vários brasileiros que se destacavam em nosso incipiente contexto de arte moderna, como Anita Malfatti (1889-1964) e Tarsila do Amaral (1886-1973). Seguindo o programa cultural proposto pela Maison, em março de 1924 foi inaugurada ainda outra exposição, dessa vez maior, no museu Galliera, cedido para o evento pelo governo francês. A mostra recebeu o título de "Exposição de Arte Latino-americana"11, contando com sessões de pintura, escultura, arquitetura e artes decorativas, sendo também divulgada na imprensa francesa, com análise dos artistas e das obras expostas, como é o caso do artigo de Raymond Cogniat, publicado na Revue de l'Amérique Latine de n. 29 , de maio de $1924{ }^{12}$

O primeiro artigo da edição de La Renaissance dedicada à América Latina aborda as artes aplicadas, com o título “Les arts apliqués dans L’Amérique Latine”, de autoria de Raoul D'Harcourt, americanista que morou no Peru e, até a data de publicação desse artigo de $L a$ Renaissance, já havia publicado um importante conjunto de textos sobre arte têxtil e música peruanas, sendo também autor do livro Les Civilisations disparus - L'Amérique avant Colombe, publicado em Paris no ano de $1925^{13}$. O artigo separa as várias áreas das artes aplicadas, concentrando-se mais na arte pré-colombiana, mas fazendo ao final alguns comentários sobre peças "modernas". O texto foi separado pelas seções de cerâmica, têxteis, arte plumária e artefatos em prata e cobre. Ricamente ilustrado, traz inclusive reproduções em cores, de objetos de diversas coleções, como a do próprio autor e do Musée d'Ethnographie du Trocadero.

\footnotetext{
${ }^{11}$ Livre tradução, no original Exposition d'Art Américan-Latin.

${ }^{12}$ Essa exposição e o subsequente artigo de Raymond Cogniat foram detalhadamente analisados por Letícia Squeff na palestra "Considerações sobre a Exposition d'Art Américan-Latin (1924)" apresentada em 1 de abril de 2015 no Colóquio Labex - São Paulo 2015 - "Uma história da arte alternativa: outros objetos, outras histórias - da História Colonial ao Pós-Modernismo", evento realizado no MAC-USP, cujas palestras estão em vias de publicação. Squeff propôs uma análise muito precisa sobre o ponto de vista de Raymond Cogniat sobre essa exposição. O discurso de Cogniat foi lido considerando a avaliação da arte latino-americana na comparação com o modelo europeu, o que colocou em evidência a questão da "origem" no discurso do crítico e da consideração de "originalidade" de uma obra, no sentido de fidelidade a uma herança cultural. Essas observações da autora contribuíram em grande medida para as análises que apresentamos aqui. Sobre essa exposição ver também o artigo de GREET, Michele. Occupying Paris: The First Survey Exhibition of Latin American Art. Journal of Curatorial Studies, v. 3, issue 2 e 3, 2014, p. 212-236.

${ }^{13}$ Cf. Raoul d'Harcourt. Journal de la Société des Américanistes. Tome 58, 1969, p. 259-263.
}

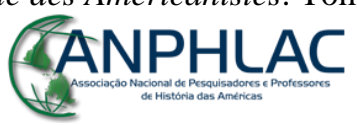

Revista Eletrônica da ANPHLAC, ISSN 1679-1061, №. 19, p. 252-267, jul./dez., 2015.

http://revista.anphlac.org.br 
Na sequência, é contemplada a arquitetura, com um artigo assinado por Louis Capitan, este também americanista, professor do Collége de France, especialista em antropologia da América Antiga, que havia também publicado diversos artigos e, especialmente em 1924, um artigo sobre os povos pré-colombianos ${ }^{14}$. Nessa edição de La Renaissance, seu artigo tem o título "L'Architecture dans L'Amérique Latine", separado, após uma breve introdução, em partes como arquitetura mexicana, peruana, colonial e moderna. Ao longo do artigo foram publicadas diversas reproduções de fotografias dos monumentos analisados, estas do acervo do próprio autor.

O terceiro artigo é finalmente o de Raymond Cogniat (1896-1977), autor que escrevia assiduamente críticas de arte para a Revue de l'Amérique Latine nesse período, comentando sobre a atuação dos artistas latino-americanos no cenário artístico francês. A Revue de l'Amérique Latine, por sua vez, foi criada em 1922, substituindo o Bulletin de l'Amérique Latine, criado pelo "Groupement des Universités et Grands Écoles de France pour les relations avec l'Amérique Latine", inicialmente com o nome de Bulletin de la Bibliothèque Américain. ${ }^{15}$ No artigo que a seguir se apresenta a tradução, Raymond Cogniat afirmou, em uma pequena nota introdutória, que sua análise sobre os artistas latino-americanos ficaria restrita àqueles que atuavam no contexto francês daquele momento.

O artigo de Raymond Cogniat na La Renaissance foi separado por países, em ordem alfabética, apresentando várias reproduções de obras dos principais artistas de cada país, o que contribuía, naquele momento, tanto para a compreensão de suas ideias, quanto para a própria divulgação do trabalho dos artistas. Cogniat ficaria mais conhecido e ganharia posteriormente mais destaque no ambiente cultural francês por uma série de publicações realizadas nos anos seguintes, como prefácios de catálogos de exposições dos impressionistas, de Paul Gauguin e de Paul Cézanne, ou publicações específicas sobre determinados artistas ou grupos de artistas. Além dessas publicações, o autor foi também delegado na I Bienal de Paris, realizada em 1959, com organização de André Malraux.

\footnotetext{
${ }^{14}$ Cf. Maurer M. A.; Vaufrey R. Louis Capitan. Journal de la Société des Américanistes. Tome 21, n 2, 1929, p. 402-409.

${ }^{15}$ Sobre essa revista, ver também as análises de BATISTA, Marta Rossetti. Op. Cit., p. 129 e o artigo de JARRIGE, Pierre. La Revue de l'Amérique Latine, historia e ideas. Redial-Revista Europea de Información y Documentación sobre América Latina, n. 5, 1994, p. 98-99. Disponível em: http://www.red-redial.net/revistaredial,revista,europea,de,informacion,y,documentacion,sobre,america,latina-283-1994-0-5.html. Acesso em: 23 de março de 2012.
}

\section{CANPHLAC}

Revista Eletrônica da ANPHLAC, ISSN 1679-1061, Nº. 19, p. 252-267, jul./dez., 2015.

http://revista.anphlac.org.br 


\section{Os Pintores da América Latina [Raymond Cogniat]}

Não pretendemos apresentar aqui um quadro geral da pintura da América Latina, mas enumerar brevemente os artistas que, na França, conseguiram se destacar, seja nos salões anuais, seja em exposições particulares. Veremos que neles, mais do que em quaisquer outros, as técnicas e os gêneros mais opostos encontram defensores e mesmo adeptos.

O que aparece indiscutível, em primeiro lugar, é a influência considerável da França. A lição do impressionismo ali ainda é muito viva e é nela que se baseia a maioria dos pintores. Mesmo entre os mais modernos, muitos ainda não o esqueceram. Fato surpreendente, os ultramodernos são poucos.

Desses países novos, audaciosos, que têm uma tradição artística muito rica, mas muito diferente do nosso passado, esperava-se uma extraordinária renovação das fórmulas artísticas, ou simplesmente uma séria transposição de nossas concepções europeias.

Isso ainda não se produziu e, sem dúvida, por muitas razões. Os latinos que são expatriados tentaram conservar um contato estreito, uma lembrança fiel da pátria, de suas tradições e gostos; assim eles reagiram inconscientemente contra tudo o que podia ser suscetível de provocar deformações, ou simplesmente uma modificação de sua concepção de beleza. As piores excentricidades que foram entre nós acolhidas, sob o pretexto de novidade, graças ao seu caráter exótico, apenas inspiraram as desconfianças de nossos irmãos latinos.

A arte que floresceu anteriormente na América reaparecerá um dia renovada, reanimada por uma cultura que será capaz de se adaptar a um meio particularmente rico. As promessas de hoje prenunciam belos resultados e se observarmos o esforço considerável realizado apenas em alguns anos, podemos esperar muito.

A arte moderna na América do Sul ainda se dedica a estudos que já ultrapassamos. Nossas lições não serão úteis aos artistas que queiram afirmar sua personalidade. Muito se censura por procurarem sempre suas diretivas na Europa. É difícil reagir bruscamente contra uma tradição natural, e apenas conseguimos depois de hesitações, dúvidas e erros.

Não há unidade entre os diversos artistas dos quais devemos falar. Mas por acaso existe essa unidade entre os pintores franceses? No mais é muito difícil falar de unidade em uma época contemporânea. O melhor é escutar a emoção pessoal, sem procurar estabelecer classificações, que são sempre arbitrárias.

\section{GANPHLAC}

Revista Eletrônica da ANPHLAC, ISSN 1679-1061, Nº 19, p. 252-267, jul./dez., 2015. 
Um gênero no qual a América do Sul merece muitos elogios é a caricatura. Sem dúvida a fantasia dos latinos encontrou nela um terreno favorável e, com o pretexto de rir, os artistas não se prendem a leis muito rígidas de sua concepção de arte. Parece que na caricatura deram livre passagem a toda originalidade que não ousam expressar na pintura. Na caricatura já não desconfiam mais das deformações, e as empregam sempre logicamente. É uma pena que tais dons sejam utilizados apenas nesses divertidos desenhos, e tão rapidamente esquecidos quando se trata de obras sérias, que mais parecem exercícios de alunos dedicados.

O que se espera da América Latina é essa mistura de refinamento e vigor, a expressão moral de um país ao mesmo tempo novo e velho, a síntese prodigiosa do mundo moderno.

\section{A República Argentina}

Vimos, há alguns meses, na Exposição de Arte Argentina, organizada no Jeu de Paume, os principais pintores da grande República Sul-americana. O conjunto, resultado de uma seleção minuciosa, revelou a importância considerável que o impressionismo tem naquele país e mostrou que as tentativas ultramodernas ainda não têm muitos adeptos. Nenhum dos artistas argentinos que vivem em Paris se ligou aos movimentos recentes.

É necessário mencionar como exceções Alfredo Guttero, que realizou composições originais, e, sobretudo, Chas Laborde. Mas esse último está tão inserido no movimento francês contemporâneo, que é difícil isolá-lo de nossos artistas. Ele empregou uma observação aguda e muito pessoal às ilustrações de livros e ao estudo dos meios tão pitorescos das mulheres. Uma exposição recente mostrou que o grande ilustrador era também um excelente pintor, ainda que menos livre.

De Alfredo Guido indicamos as belas águas-fortes; de Antonio Terry e Alfredo Gramajo Gutiérrez, as cenas regionais curiosamente compostas; e de Hector Basualdo, os nus intensamente tratados. Quanto a Quinquela Martín, o Sr. Jean Guiffrey falou aqui mesmo de sua obra, deste "formigueiro de porto moderno, da impressionante massa de formidáveis barcos ao longo do cais, animados por centenas de homens carregando e descarregando-os". ${ }^{16}$

\footnotetext{
${ }^{16}$ Aspas no original.
}

\section{GANPHLAC}

Revista Eletrônica da ANPHLAC, ISSN 1679-1061, Nº 19, p. 252-267, jul./dez., 2015. http://revista.anphlac.org.br 
Citamos ainda o Sr. Alcorta, que ainda não encontrou completamente seu próprio meio de expressão, o Sr. Ramaugé já bastante independente, e os senhores Bernier, Gavazo e todos os artistas que participaram desta Exposição de Arte Argentina, que não poderíamos fazer aqui uma simples enumeração, insuficiente para dar uma ideia de suas obras diversas e sinceras.

\section{O Brasil}

O Brasil, com alguns artistas de valor, está no caminho para tomar o primeiro lugar na pintura moderna da América Latina.

Citaremos primeiramente Rego Monteiro, que está ainda em plena evolução. Em tão pouco tempo, o Sr. Rego Monteiro encontrou uma fórmula bem pessoal, uma realização plástica original e forte. Ele demonstrou em uma grande composição intitulada Combate um senso decorativo real. Depois, em um nu feminino, seu gosto por linhas flexíveis, ondulosas. Mais tarde, levado por uma construção quase arquitetural, colocou em suas composições uma estilização deliberada, por vezes muito massiva. Agora, sintetizando todas as tendências, oferece obras em que a graça e a força se harmonizam.

Muito interessantes são também as telas da Srta. Tarsila, embora geralmente influenciadas por Fernand Léger, mas um Fernand Léger mais sensível, menos cerebral. Não é preciso procurar muito para descobrir na Srta. Tarsila, atrás dessa estilização, uma elegância, uma delicadeza muito feminina. Pode-se esperar muito desta artista.

O Sr. Toledo Piza expõe regularmente nos diversos salões, por isso será fácil seguir sua evolução. Ele retomou o problema que atormentou Cézanne e sentiu naturalmente a influência do mestre.

O Sr. Tulio Mugnaini expôs obras decorativas muito boas, alguns nus e, sobretudo, pitorescas paisagens bascas, vivamente coloridas.

Outros artistas brasileiros apresentaram telas nos diversos salões. Eles mostraram com suas realizações dons diversos e relativamente desiguais.

O Sr. Cavalleiro por mais de uma vez demonstrou qualidades verdadeiras de colorista, assim como Angelina Agostini. Gaston de Fonseca é, sobretudo, voltado para o retrato. Citamos ainda a Srta. Malfatti, que tem demonstrado frequentemente uma bela

\section{GANPHLAC}

Revista Eletrônica da ANPHLAC, ISSN 1679-1061, N. 19, p. 252-267, jul./dez., 2015. http://revista.anphlac.org.br 
sensibilidade, mas que parece ter medo de sua própria originalidade, enfim Dutra, Belmiro, Colin, Madruga.

\section{Chile}

O Chile parece preferir manter-se longe das pesquisas da pintura moderna, com exceção de um pintor extraordinariamente talentoso, a quem se devem obras originais ou cheias de promessas, o Sr. Ortiz de Zárate, que, sem ser de nacionalidade chilena, foi assimilado aos artistas desse país, por ter lá vivido durante muito tempo.

Do Sr. De Sangroniz, conhecemos os retratos que indicam seu gosto pela suntuosidade profunda das cores, pela intensidade de certos reflexos quase metálicos.

Os outros artistas chilenos que vimos na França demonstram uma verdadeira consciência artística e testemunham um métier honestamente adquirido e escrupulosamente respeitado: Plaza-Ferrand, Valenzuela Llanos, Dorlhiac, Srta. Castro e enfim o Sr. Bonnencontre que nos mostrou algumas paisagens das montanhas, realmente impressionantes.

\section{Colômbia}

A Colômbia tem um passado artístico rico demais para esperar que as artes plásticas saiam do período de pesquisas e de tateamento que passam atualmente no mundo inteiro. Também os espíritos mais curiosos e refinados de lá são mais atraídos pelas letras e as ciências, nas quais podem dar a medida de sua grande cultura. Os artistas colombianos são pouco numerosos por aqui e suas obras pouco conhecidas. Os Srs. Medina, Pizano, de Santa Maria expõem irregularmente. É difícil e, sobretudo, injusto fazer um julgamento, já que vimos apenas uma ou duas telas de um artista. É preciso considerar ainda que um país cujo passado artístico é tão rico tem muito mais dificuldade em evoluir, já que está atrelado à tradição.

\section{Cuba}

\section{GANPHLAC}

Revista Eletrônica da ANPHLAC, ISSN 1679-1061, №. 19, p. 252-267, jul./dez., 2015. 
É de Cuba que se pode destacar um dos artistas mais discutidos dentre os pintores da extrema vanguarda: o Sr. F. Picabia. Ele está acostumado a escutar todas as opiniões no que lhe concerne, desde entusiásticos elogios a sarcasmos e insultos. Merece ele um ou outro? Para nós, seu caso se mostra quase trágico. Nesse incessante esforço que os artistas fazem para se afastarem de si mesmos, do convencional, do já feito, esforço mais consciente que nunca, o Sr. Picabia tentou esperar o impossível e o excesso de seu desejo não lhe permitiu conservar nenhum controle sobre si mesmo. Ele tornou-se a vítima deste esnobismo que está ligado aos artistas modernos e tem ido sempre além de si mesmo. Talvez seja com a mais perfeita boa intenção que seu temperamento de pintor o conduziu a tudo o que é menos pictórico possível. Riem muito de Picabia. É simplesmente um caso, e um dos mais curiosos na evolução moderna.

Armando Maribona e Jiménez Armengol, na caricatura, sabem mostrar uma fantasia, uma liberdade que são menos perceptíveis em sua pintura. Os dois chegam a uma completa estilização dos personagens em alguns traços, simples e flexíveis.

Enfim, citamos o Sr. Hernández Giro que é especialista em aquarela e fez obras curiosas com essa técnica.

\section{Equador}

O pequeno número de pintores equatorianos que conhecemos em Paris não é suficiente para darmos uma ideia geral da produção artística deste país, mas suas características anunciam um gosto vivo pela cor e um espírito aberto às pesquisas mais modernas. É assim que o Sr. Rendon conseguiu obter realizações pessoais, após várias etapas. A organização de suas composições é determinada por massas coloridas, sem grande recurso ao desenho. Os elementos materiais da tela (personagens, casas, árvores etc.) são considerados apenas como simples pretextos e são rapidamente esboçados por um traço.

Outra artista desse país, Sra. Villanueva, revelou-nos em uma recente exposição um talento de pintor sólido, seguro de seu ofício. Seus nus são cheios de força e suas naturezasmortas se incluem na boa tradição impressionista.

\section{GANPHLAC}

Revista Eletrônica da ANPHLAC, ISSN 1679-1061, N. 19, p. 252-267, jul./dez., 2015. 
Enfim, o Sr. Camilo Egas nos mostrou retratos interessantes de tipos locais e o senso de precisão que o guia demonstrou mais de uma vez a marca de sua personalidade.

\section{O México}

Dentre os povos da América Latina, o México é o que mais deu provas de suas qualidades e de seus dons artísticos. Poucos artistas mexicanos vivem em Paris, mas nenhum é insignificante e o mais famoso dentre eles, Angel Zárraga, tem um lugar justamente invejado na pintura contemporânea. Pesquisador voraz, curioso dos novos processos, Zárraga não ficou indiferente diante dos trabalhos dos cubistas; mas, se foi seduzido por essa técnica e se aproveitou de sua lição, soube se destacar e conservar uma personalidade bem marcada. Seu gosto por grandes superfícies coloridas o leva ao afresco e às vastas decorações murais. Apenas assinalamos este artista, já que nosso leitor ainda guarda na memória o belo artigo que a Srta. Louise Hervieu lhe consagrou, nessa mesma revista, no mês de junho. Contudo, consideramos ainda curioso reproduzir dele duas telas que apresentam o mesmo assunto, mas tratado por dois processos muito diferentes.

Vem do México igualmente uma jovem artista, Srta. Rosario Cabrera. Porém, enquanto Zárraga é um pintor daqui, tanto por sua técnica quanto pela escolha de alguns assuntos, a Srta. Cabrera nos traz os tipos de seu país ou paisagens muito características. Sua técnica é menos sólida, mas ela já demonstra uma extraordinária maturidade, apesar de ser tão jovem, sobretudo com uma visão muito individual.

O Sr. Benjamin Coria trouxe da Itália alguns retratos interessantes e belas composições. Observou-se dele, em um Salão recente, um retrato de mulher que era uma bela harmonia de cinzas e marrom. Ele realiza uma interessante simplificação de linhas e de cores, mas é nas naturezas-mortas, sobretudo, que ele acusa sua personalidade.

Muito conhecido é o nome de Rivera, que viveu algum tempo na França, sendo útil insistir sobre o valor de tão belo artista, cujas composições lembram às vezes as obras dos pintores primitivos. Citamos ainda Rodriguez Lozano e Castellanos, que expuseram há algum tempo em Paris e que, eles também, souberam aproveitar da lição do cubismo e estão preocupados, como a maioria dos pintores modernos, com as questões de construção.

\section{GANPHLAC}

Revista Eletrônica da ANPHLAC, ISSN 1679-1061, Nº 19, p. 252-267, jul./dez., 2015. 
Da bela atividade artística do México, o Sr. Alfredo Ramos Martínez, diretor da Escola de Belas-Artes, acaba de nos dar uma prova brilhante, em uma exposição de desenhos de crianças, que é uma verdadeira revelação.

\section{O Peru}

Quase todos os pintores peruanos que vimos na França parecem ligados às velhas tradições pictóricas, suas personalidades mal se destacam. Há dentre esses artistas, contudo, dois caricaturistas interessantes, os Srs. Grenet e Cárdenas, e, sobretudo, um excelente pintor de paisagens, o Sr. E. D. Barreda que se destaca ao captar a luz sobre as árvores ou o colorido do movimento da água. Sua técnica, que ele tirou evidentemente do impressionismo, lhe permite belos efeitos pictóricos e prova que ele assimilou perfeitamente uma concepção que outros simplesmente utilizaram sem colocar um traço pessoal, tão importante. O Sr. Cárdenas Albarracín mostrou grande preocupação com a precisão em diversos retratos e composições.

\section{Uruguai}

O artista mais representativo que conhecemos do Uruguai é o Sr. Pedro Figari, um dos mais belos temperamentos que nos revelou a América do Sul. O Sr. Figari soube usar a luz e imprimir sua forte personalidade a telas que são pitorescas apenas pelo assunto tratado. Ele soube passar do imprevisto da anedota e impor sua técnica onde outros viram apenas personagens curiosos a reproduzir. Ele os recriou de forma a dar uma vida nova, um tipo de existência pictórica. São obras de um artista que soube animar seus quadros unicamente com procedimentos de pintor.

A França conheceu igualmente Blanes Viale, hoje Diretor das Artes e Ofícios de Montevidéu, pintor impressionista muito interessante, assim como Cuneo, que apreciou as experiências de Cézanne, e o Sr. Castellanos y Milo Baretta, também impressionista, que teve, entre outros, o raro mérito de ser um dos primeiros da América do Sul a apreciar e reunir uma coleção de pintores modernos.

\section{GANPHLAC}

Revista Eletrônica da ANPHLAC, ISSN 1679-1061, N. 19, p. 252-267, jul./dez., 2015. 


\section{Venezuela}

A Venezuela, ao menos pelo que conhecemos na França, parece ainda em pleno período de evolução, ainda que artistas como os Srs. Cabré, Otéro, Vera, em muitas exposições nos deram prova da mais indiscutível de suas qualidades, em suas paisagens e em retratos honestos, sinceros, de uma construção consciente. Na paisagem, afirmam também sua preferência pelo impressionismo que compreenderam e que lhe serve ainda com fervor.

Raymond Cogniat. [Tradução Renata Gomes Cardoso]

\section{Referências Bibliográficas}

ALEXANDRE, Arsène. Les Renaissances et les Crises de l'Art Français et des Industries Artistiques. La Renaissance de l'art français et des industries de luxe, n.1, março, 1918, p. 12 .

BATISTA, Marta Rossetti. Os artistas brasileiros na Escola de Paris - Anos 20. Tese de doutorado, USP, 1987.

DESBIOLLES, Yves Chevrefils. Les revues d'art à Paris 1905-1940. Presses Universitaires de Provence, 2014.

GREET, Michele. Occupying Paris: The First Survey Exhibition of Latin American Art. Journal of Curatorial Studies, v. 3, issue 2 e 3, 2014, p. 212-236.

JARRIGE, Pierre. La Revue de l'Amérique Latine, historia e ideas. Redial-Revista Europea de Información y Documentación sobre América Latina, n. 5, 1994, pp. 98-99.

La Renaissance de l'art français et des industries de luxe. Paris, n. 1-12, 1918-1926.

SILVER, Kenneth E. Esprit de corps: the art of the Parisian avant-garde and the First World War,1914-1925. Princeton: Priceton Univ., 1989.

\section{GANPHLAC}

Revista Eletrônica da ANPHLAC, ISSN 1679-1061, №. 19, p. 252-267, jul./dez., 2015. 